\title{
Entesentar-s \\ Legal issues when a doctor's relationship with a "difficult" patient breaks down
}

Loane LC Skene
LLB, LLM, LLD

LLB, LLM, LLD

Melbourne Law School, University of Melbourne,

Melbourne, VIC.

I.skene@unimelb.edu.au

doi: 10.5694/mjal3.11019

\begin{abstract}
3.13 Ending a professional relationship
In some circumstances, the relationship between a doctor and patient may become ineffective or compromised, and you may need to end it. Good medical practice involves ensuring that the patient is adequately informed of your decision and facilitating arrangements for the continuing care of the patient, including passing on relevant clinical information.
\end{abstract}

\section{A code with legal consequences}

The provisions of the Code may have legal effect, despite not being legislation or case law. The Code is a statement of accepted practice within the medical profession, developed after extensive consultation with the profession and the wider community. It could be cited in court as evidence of what "reasonable care" requires - for example, in legal proceedings for alleged negligence (a failure to take reasonable care) - or breach of contract (a breach of an implied obligation to take reasonable care in medical consultations and treatment). A patient who has suffered an injury or loss because their doctor failed to inform the patient about ending the relationship, or did not make suitable arrangements for the patient's continuing care, could sue the doctor for compensation for that injury or loss, in either negligence or contract, alleging failure to take reasonable care.

A doctor who does not comply with the Code might also be subject to disciplinary action under the National Law. Any member of the public could make a notification to the Australian Health Practitioner Regulation Agency, alleging a breach of professional standards. If that is established, a tribunal might issue a caution or reprimand; impose a fine or conditions on registration; or even suspend or cancel the practitioner's registration.

The doctor's obligation under the Code to adequately inform the patient and to facilitate "arrangements for the continuing care of the patient"1 ${ }^{\prime 1}$ will be open to interpretation. However, emphasis is likely to be placed on the needs of the particular patient rather than practice within the profession in providing information to the patient. ${ }^{2}$ Although the defence of peer professional opinion has been restored in a modified form in the legislation in all states and territories for tort law reform (the civil liability legislation), the amendment applies only to

\author{
Summary \\ The legal duties of a doctor attending a "difficult" \\ patient with a serious condition do not end at the last \\ consultation, especially in a small rural community. \\ - Doctors have a continuing obligation to ensure that the \\ patient's health is not impaired because the clinical \\ relationship has ended. \\ This article suggests some steps that a doctor could \\ take to fulfil the legal obligation in such a case.
}

treatment. It does not apply to providing information and a patient-centred standard is applied in determining the information to be provided. Evidence of the practice of other doctors may be relevant to what is reasonable in a particular case but it is not determinative.

\section{Lessons from previous legal cases}

Three cases concerning a doctor's alleged negligent failure to follow up may be relevant in determining a doctor's legal obligations when ending a doctor-patient relationship. In two of these, patients were awarded compensation because the doctor was found negligent in:

- failing to inquire whether a patient had undergone a diagnostic procedure after the doctor gave her an admission form to take to the hospital to arrange for the procedure to be done. The hospital did not tell the patient the date for the procedure and it was delayed for 5-6 months. When the test was done, it showed cancer that might have been treated if discovered earlier; ${ }^{3}$ and

- failing to follow up when the doctor did not receive a cytology report from a pathology laboratory after a patient's needle biopsy. The doctor had arranged for the patient to ring him for the results; she did not ring or attend the follow-up appointment. ${ }^{4}$

In the third case, the doctor was found not negligent. ${ }^{5}$ The patient alleged that the doctor failed to follow up after recommending a blood test for $Q$ fever, described as a "notorious ... communicable disease among abattoir workers". The patient could have been vaccinated if the test was positive. The patient was infected but did not undergo the test or attend for a follow-up appointment (he denied receiving the form for the test). The doctor did not try to contact the patient when the patient failed to attend the next appointment. The doctor said "I don't think in 2002 if a patient fails to attend for a pathology test it was my responsibility to follow that up". The court accepted this argument on the facts of the case. The patient was "seemingly of reasonable intelligence and able to comprehend the meaning of a low positive result and the fact he would not be immunised at that time". He could decide not to have the test. The condition was serious 
Checklist: ending a relationship with a patient at a critical stage in treatment

- To adequately inform patients, doctors should give written notice of their intention to end the relationship, preferably by certified mail, requesting acknowledgement of receipt.

- Doctors should include in the notice a brief explanation for ending the relationship, such as the patient failing to comply with advice or to keep appointments.

- To facilitate "arrangements for the continuing care of the patient", doctors should offer to continue to provide treatment and access to services for a reasonable period of time, such as 30 days, so that the patient can find another doctor. This is especially necessary if the patient may have a serious or lifethreatening condition that needs urgent attention; or the patient has a nonEnglish speaking background.

- Doctors should assist the patient as needed to find another doctor or specialist in the patient's vicinity to take over the patient's care.

- Doctors should offer to provide a report to the new doctor or to send copies of the patient's medical records to the new doctor, if the patient authorises that in writing.

- Doctors should answer any questions that the patient raises and try as far as possible to maintain civil relations with the patient.

but not life-threatening as it was in the first case above of "a patient presenting with signs consistent with a malignant tumour who fails to re-attend or undergo relevant pathology tests". ${ }^{3}$ There was nothing to suggest to the doctor that the patient would decide not to have the test. The doctor's duty to follow up might be different if a patient does not speak English, or has an intellectual impairment; or if the patient's condition may be life-threatening. The court listed factors that were relevant in deciding whether the doctor had a continuing obligation to the patient. These included the patient's family history of cancer, continued bleeding without diagnosed cause, previous compliance with suggested procedures and tests, 10-year relationship with the doctor, and non-English speaking background.

Although these cases concerned a failure to follow up, similar principles might be suggested in deciding what duties a doctor may have in ending a relationship with a difficult patient at a critical stage (Box). These suggestions are based on paragraph 3.13 of the Code and the standard of reasonable care under the civil liability legislation in all states and territories, and the common law. The steps suggested could be adopted in any case where a doctor-patient relationship has ended, regardless of the reason - a difficult, non-compliant or threatening patient, or the doctor's cessation of employment, relocation or retirement, taking account of the possible impact on the patient if the relationship has ended.

\section{Ensuring a patient's continuing care}

The above steps may not always resolve the issues. There may be no other doctor or specialist in an isolated rural area to whom the patient can be referred; or the doctor may be concerned about how such a referral should be made. Where a patient may present a serious risk to the new doctor, the doctor's duty of confidentiality may be outweighed by the need to protect the new doctor's safety. However, that is not the case in other circumstances, and the referring doctor would ordinarily be required not to reveal the reason for the referral if it relates to the patient (although the new doctor may guess what it is). The initial doctor may therefore feel obliged to continue treating the patient, perhaps seeking assistance from a more distant colleague, if that is possible.

If it is necessary to terminate the clinical relationship, the treating doctor may take comfort from the fact that any litigation or other risk in such circumstances can be minimised by telling the patient that they should terminate their clinical relationship, and by ensuring that what happens afterwards is in accordance with what the doctor perceives to be the patient's best interests (especially in regard to facilitating transfer of care).

Competing interests: No relevant disclosures.

Provenance: Commissioned; externally peer reviewed.

1 Medical Board of Australia. Good medical practice: a code of conduct for doctors in Australia. http://www.medicalboard.gov.au/Codes-Guidelines-Policies/Code-ofconduct.aspx (accessed Aug 2014).

2 Rogers v Whitaker (1992) 175 CLR 479.

3 Taiv Hatzistavrou [1999] NSWCA 306.

4 Kite v Malycha (1998) 71 SASR 321.

5 Grinham v Tabro Meats Pty Ltd \& Anor; Victorian WorkCover Authority v Murray [2012] VSC 491. 